\title{
HUGE BENIGN GRANULOSA CELL TUMOUR IN A 61 YEAR OLD NIGERIAN GRANDMULTIPARA WITH LATE PRESENTATION.
}

\author{
*G.O Igberase, **PN Ebeigbe, \\ *St Louis Clinic, Ekurede-Urhobo, P.O.Box 4246, Warri, ** College of Health \\ Sciences, Delta State University, Abraka, Nigeria
}

\begin{abstract}
Objective: To re-appraise clinicians that huge ovarian lesions with features of malignancies may still be benign and that late presentation is a problem in genital cancer management that should be addressed.
\end{abstract}

Subject, material and method: $A$ case report of a huge benign granulosa cell tumour in a postmenopausal woman is presented.

Results: She presented as a case of a huge right ovarian tumour with weight loss, respiratory and abdominal discomfort one year after initial diagnosis was made because of fear of surgery. She had laparotomy, total abdominal hysterectomy and bilateral salpingoophorectomy. Histology revealed granulosa cell tumour of the benign type.

Conclusion: Huge ovarian tumours in the elderly could be benign. In the absence of proper screening technique for ovarian cancers, laparotomy for histological purposes is required. Health education and proper counselling is imperative to reduce delays of patients to hospitals.

Key Words: Huge, benign, granulosa cell tumour, 61 year old, Late presentation.

\section{INTRODUCTION}

\section{ORIGIN}

In the developing graafian follicle, the central core of granulosa cells is surrounded by the theca cells derived from the ovarian stroma. After ovulation, some granulosa cells remain in the corpus luteum, and remain separate from a layer of theca cells of varying thickness. In rare cases, approximately one fifth as frequently, Sertoli cells similar to those supporting cells of the testis, are also found in the ovary, leading to a Sertoli-Leydig cell tumour (otherwise called "androblastoma"), which may be virilising, endocrinologically inactive or oestrogenic. In the tumours derived from these elements, the proportion of these cell types which produce oestrogen (or occasionally androgen) is highest in granulosa cell tumour, and relatively rare in the other tumours.

\section{PRESENTATION}

The majority are stage I tumours and have a relatively good prognosis. Granulosa cell tumours are the most common and may be oestrogen producing leading to precocious puberty, amenorrhoea, peri-menopausal bleeding and virilising symptoms $^{1}$. Significant clinical changes of hyperestrogenism are evident in less than $15 \%$ of patients at presentation. Some are associated with ovarian hyperstimulation following infertility 
treatment, and there is also an association with the Peutz-jeghers syndrome $^{1}$. The prognosis of granulosa cell tumours is generally good, which may reflect their early stage and good differentiation. It should be noted that there is small risk of delayed relapse as late as 25 years after initial presentation so long term follow up is advised ${ }^{2,3}$. Serum tumour markers include oestradiol, FSH, $\mathrm{LH}$ and serum inhibins ${ }^{4}$.

\section{PATHOLOGY}

It is recognized that this group of tumours is rare and the diagnosis is frequently difficult. It is therefore strongly recommended that tumours in this category be subject to detailed review by an expert gynaecologic pathologist. Furthermore, additional slides and/or tissue blocks should be retained for future molecular analysis.

\section{TREATMENT}

In younger pre-menopausal women with localised disease, there may be a role for conservative fertilitysparing surgery. This would include at a minimum, removal of the affected ovary and extended surgical staging. If fertility is not an issue, then a complete hysterectomy with bilateral salpingoophorectomy and omentectomy are appropriate. In those women with more advanced disease, surgical debulking adopting the general principles applied in epithelial ovarian cancer should be considered ${ }^{5}$.

\section{CHEMOTHERAPY}

There is no role for adjuvant chemotherapy on a routine basis. For those women with macroscopic or microscopic residual disease (i.e. Stage II - IV) cisplatinum based chemotherapy has been the most commonly utilized either combined with vinblastine and bleomycin or adriamycin and cyclophosphamide. Most authors would now recommend the use of bleomycin, eptoposide and platinum (BEP) for a minimum of 3-4 cycles $^{6,7}$ There is a current Gynaecologic oncology group $\{G O G$ \} trial (GOG $\# 187$ ) that is seeking to identify the role of taxanes in the management of these women ${ }^{8}$ Carboplatin and paclitaxel may become established as an alternative first line therapy. ${ }^{9}$

A more frequent clinical setting than a primary diagnosis of advanced granulosa cell tumour is that of a woman presenting with recurrent granulosa cell tumour. In this situation, cytoreductive surgery should be the primary approach with systemic chemotherapy as above for residual disease. If the recurrent disease is not resectable at the time of presentation, one may consider 2-3 cycles of BEP (or carboplatin and paclitaxel) pre-operatively and follow interval cytoreductive surgery with another 2-3 cycles. ${ }^{7,9}$

The need for additional clinical trials of sufficient size to provide good evidence of efficacy is required in this area. Given the rarity of these tumours, international collaboration is needed to achieve this aim. Markers used for diagnoses and monitoring of granulosa cell tumours include serum inhibin, mullerian inhibiting substance, oestrogen, progesterone, luteinising and follicle stimulating hormones. None of these has become established in routine use.

\section{CASE REPORT}

Mrs E.V, a 61 year old para $6+0$ who was 10 years postmenopausal presented at the gynaecological clinic of the Baptist Medical Centre in March 
of 2004 with a history of abdominal swelling of 12 months duration. She was a known diabetic on oral hypoglycaemic agent. Swelling was first noticed as a suprapubic mass when she presented for her routine check up in the medical outpatient a year ago. Ultrasound scan done then revealed a complex right ovarian cyst. She was counselled for surgery but defaulted. Abdominal swelling grew rapidly in the last 3 months and was associated with mild respiratory and abdominal discomfort necessitating her presentation in hospital. There was associated weight loss. Bowel motion was once daily and stools were watery. There was no abdominal pain but appetite was reduced. She neither had cough nor chest pain. There was no bleeding or discharge per vaginam. Menarche was at 15 years of age and there was no past history of oral contraceptive use or oestrogen preparations. There has been no family history of breast, ovarian or colonic cancers. She had 6 normal deliveries from 1963-1984 and all the children were breastfed. She was a trader married to a retiree in a monogamous setting. She neither smoked cigarettes nor drank alcohol. Late presentation was due to fear of surgery.

On examination, she was chronically ill looking, slightly pale, her chest was clinically clear and her cardiovascular system was stable. Abdominal examination revealed a uniformly enlarged mass compatible with a 36 week pregnant uterus. It was firm to hard, not mobile, irregular and non tender. There was associated ascites. Vagina examination showed oedematous vulva and vagina, healthy cervix and the uterus could not be delineated. The pouch of Douglas was free. The rectal mucosa was free. A diagnosis of ovarian cancer was made. Her packed cell volume was $34 \%$ She had a normal electrolyte and urea level, chest $\mathrm{x}$-ray and tested negative for HIV 1and 11. Fasting blood sugar was $167 \mathrm{mg} / \mathrm{dl}$. Liver function test was also normal. Ultrasound scan revealed a huge multiseptate cystic intraabdominal mass with a thick wall. The uterus was not visualized. She had a right ovariectomy, total abdominal hysterectomy and left salpingoophorectomy after stabilization of her glucose level. Findings at surgery were mild ascitic peritoneal cavity, huge right ovarian cyst measuring $37 \mathrm{~cm} / 29 \mathrm{~cm}$ as in figure $1 \mathrm{a}$, weighing $8.3 \mathrm{~kg}$ with a thick smooth wall without excrescences on surface. The cyst contained 6liters of serosanguinous fluid. The left ovary was atretic without evidence of malignancy. The uterus was small but normal. The bowels were adherent to the mass on the posterior surface and were separated. The abdominal organs were normal. Ascitic fluid did not show malignancy. The surgical specimen showed tumour composed of sheets and trabeculae of granulosa cells. Small follicles and Call-Exner bodies interspersed in the sheets and trabeculae of granulosa cells. The final diagnosis was that of granulosa cell tumor. She had an uneventful postoperative period and was discharged home to be seen at the gynaecology clinic. She was clinically stable when she was seen 3 weeks later. She is to be followed up for life. 


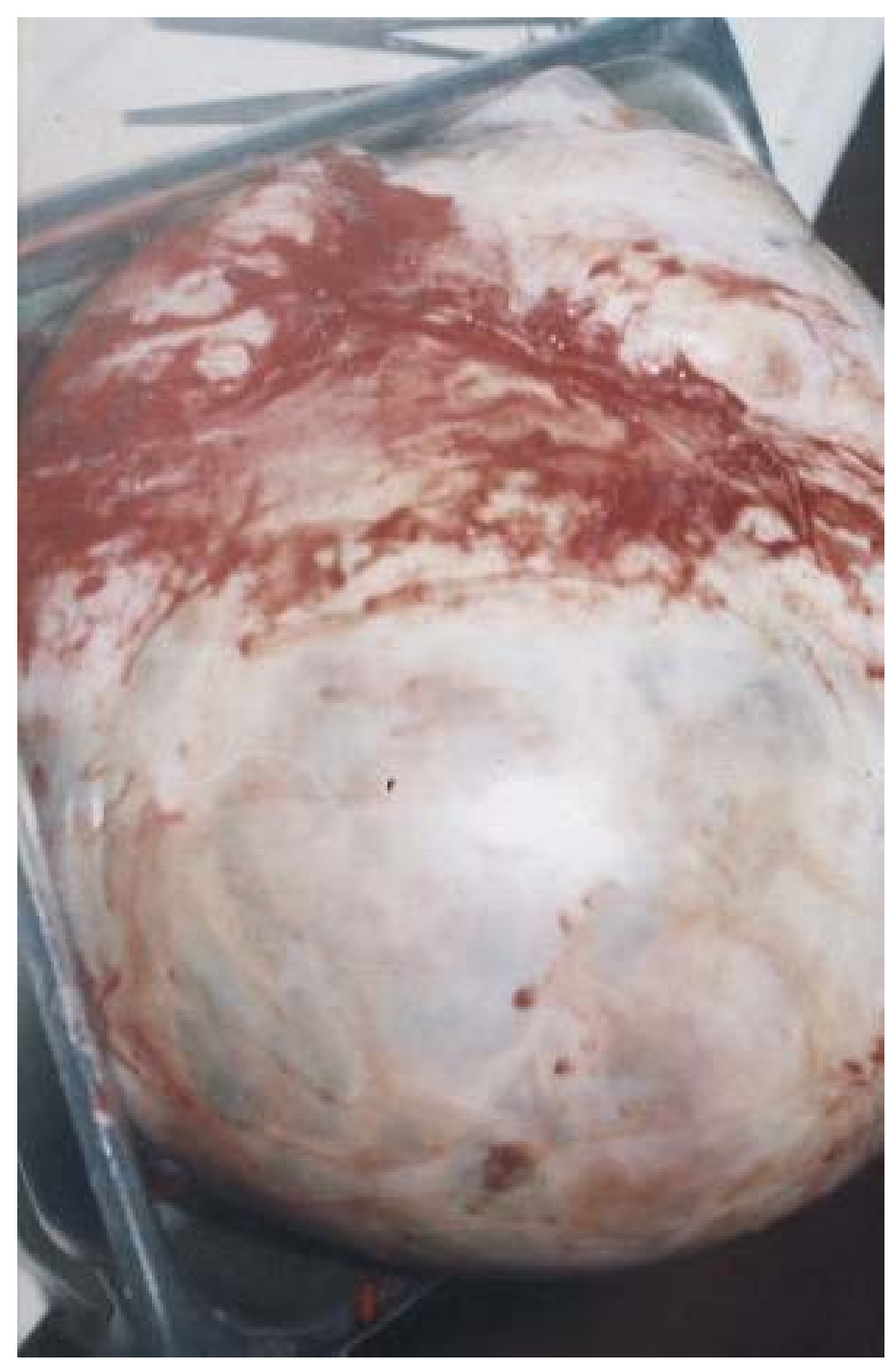

Figure 1a: Macroscopic view and

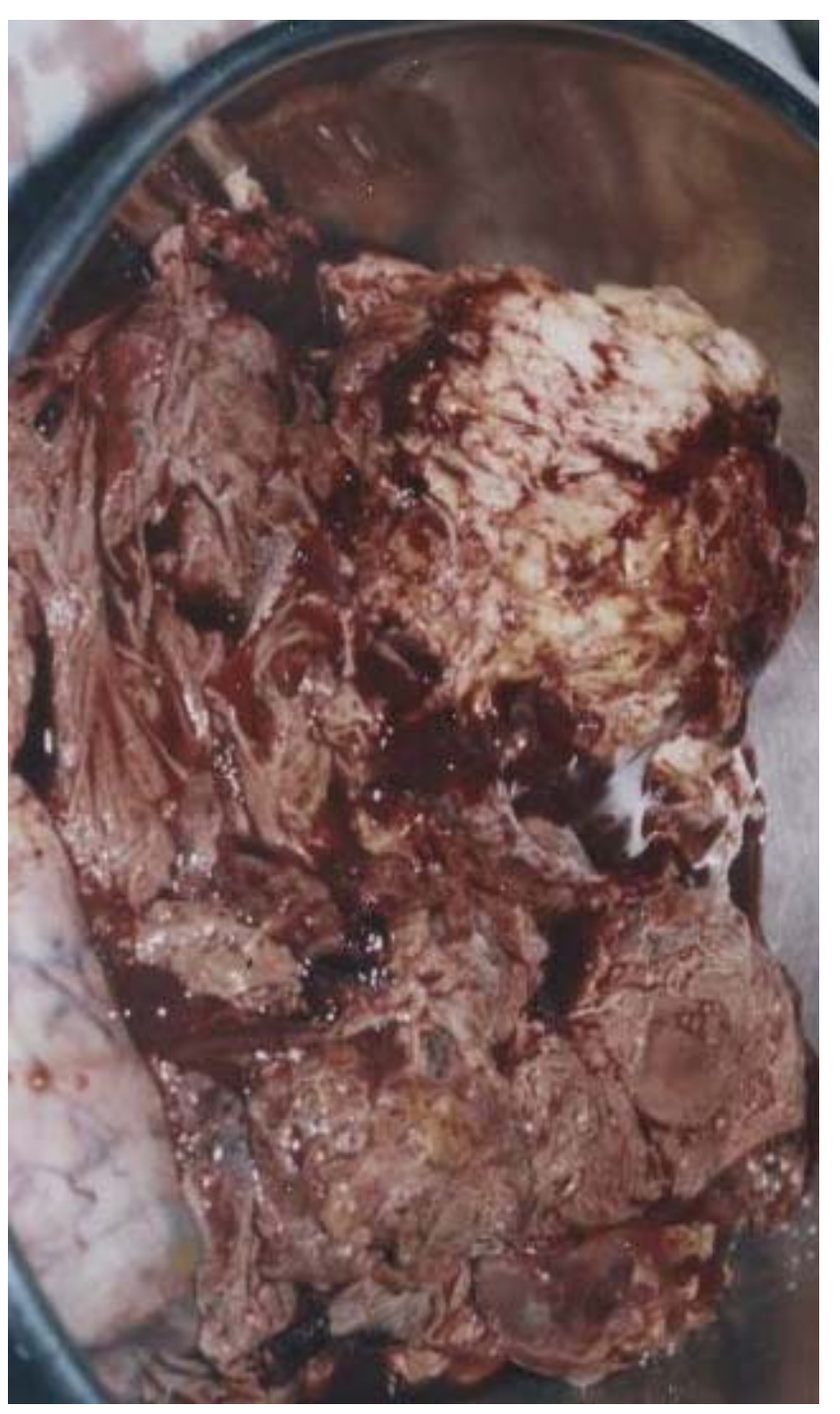

Figure 1b: Cut section of granulosa tumour. 


\section{DISCUSSION}

Granulosa cell tumours belong to the sex cord stromal group and include tumours made up of granulosa cells, theca cells and fibroblast in varying degrees and combinations. It accounts for approximately $2 \%$ of all ovarian tumours and can be divided into adult type (95\%) and juvenile type (5\%) based on histologic findings. These tumours have a propensity for indolent growth and late recurrence; they may even recur $2-3$ decades after initial treatment ${ }^{2,3}$. Both subtypes are oestrogen producing and this could be the reason for early diagnoses. Mrs E.V presented as a result of increasing abdominal swelling and respiratory distress. There was no history of oestrogenisation effects such as post menopausal bleeding. Most patients will present with one or a combination of symptoms such as vaginal bleeding, abdominal distension and/or abdominal pain ${ }^{10}$. However, despite the rather large lesion at diagnosis, $80 \%-90 \%$ of patient will present with stage 1 disease and it is usually unilateral in $95 \%$ of cases as in this patient ${ }^{10}$.

Late presentation of patients to hospitals especially in cases due to genital malignancies is a common feature in our environment. Various reasons attributable to this range from poverty, ignorance, superstitious beliefs and fear of surgery. Mrs E.V delayed for 1 year prior to presentation because of fear of death from resultant surgery. If this were a malignant lesion, she would have either presented dead or terminally ill.

Treatment of postmenopausal women is total abdominal hysterectomy and bilateral salpingo- oophorectomy while salpingo-oophorectomy may be acceptable in younger patient wishing to preserve fertility. In developing countries where tumour markers such as inhibin and calretinin are not available, appropriate staging laparotomy and tissue biopsy for histology should be carried out. However these markers have a limitation of being positive in other ovarian lesions. Diagnosis of ovarian cancer is made on the basis of clinical, radiological, biochemical and surgical diagnosis. Definitive diagnosis is made at laparotomy with histological confirmation.

CA-125 protein is the most valuable tumour marker in the field of ovarian cancer $^{11}$. This marker is produced by most ovarian cancers. It is released in the blood during pregnancy and is produced in other conditions such as endometriosis, fibroids and diverticulitis. It is useful in monitoring therapy. Since frequent late recurrence is hallmark of granulosa cell tumour, long time follow up should be emphasized.

In conclusion, huge ovarian tumours in the elderly could be benign. Granulosa cell tumours have the propensity of becoming recurrent and malignant even when this rarely occurs. In the absence of proper screening technique for ovarian cancers, laparotomy for histological purpose is required. Increase in socioeconomic status, proper health education and counselling is imperative if we are to reduce delays in presentation of patients to hospitals in our setting.

\section{REFERENCES}

1. Chua IS, Tan KT, Lim-Tan SK, Ho TH. A clinical review of granulosa cell tumours of the ovary cases in Hong Kong. 
Singapore Med J 2001; 42 (5) 203-7.

2. Anikue C., Dawood M.Y and Kramer E. Granulosa and theca cell tumours. Obstet Gynecol, 1978; 51: 214-220.

3. Evans A.T., Gaffey T.A., Malkasian G.D and Annegers J.F. Clinicopathologic review of 118 granulosa and 82 theca cell tumours. Obstet Gynecol.1980; 55: 231-238.

4. Healy KL, Burger HG, Mamers $P$ et al. Elevated serum inhibin levels in menopausal women with ovarian tumours. $\mathrm{N}$ Engl J Med 1993; 329: 15.

5. Savage $P$, Constenla $D$, Fisher C, Shepher JH, Barton DP, Blake P, Gore ME. Clin Oncol 1998; 10 (4): 242-5. Granulosa cell tumours of the ovary: demographics, survival and the management of advanced disease.

6. Colombo N, Sessa C, Landoni F, Sartori E, Percorelli S, Mangioni C. Cisplatin, vinblastine and bleomycin combination chemotherapy in metastatic granulosa cell tumor of the ovary. Obstet Gynecol 1986; 67: 265.

7. Pectasides D, Alevizakos N, Athanassiou AF. Cisplatin-containing regime in advanced or recurrent granulosa cell tumours of the ovary. Ann Oncol 1992; 3: 316.

8. Homesley HD, Bundy BN, Hurteau JA, Roth LM. Bleomycin, etoposide and cisplatin combination therapy of ovarian granulosa cell tumors and other stromal malignancies: a gynecological Oncology Group study. Gynecol Oncol 1999; 72: 131.

9. Gershenson DM, Morris $M$, Burke TW, Levenback C, Matthews CM, Wharton JT. Treatment of poor-prognosis sex cord-stromal tumors of the ovary with the combination of bleomycin, etoposide and cisplatin. Obst Gynaecol 1996; 87(4) 527-31.

10. Hartman L.C., Young R.H., Evans M.P and Podratz K.C. Ovarian sex cord stromal tumours. In: Hoskins W.J., Perez C.A., Young R.C, (eds). Principles and practice of oncology,. Philadephia: Lippincott - Raven 1997; 1003-1024.

11. Monaghan JM. Malignant disease of the ovary. In: Edmonds DK (ed) Dewhurst textbook of obstetrics and gynaecology for postgraduates, Blackwell Science publishers, 1996, pp 590-601. 